\title{
The effect of paired neutral stimuli on the acquisition and extinction of the classical eyeblink response
}

MARK OMINSKY AND GREGORY M. POSNICK ${ }^{2}$ DUKE UNIVERSITY

The effect of pairing two neutral stimuli at the same interstimulus interval subsequently used for conditioning the eyeblink response was compared to an unpaired control group and no differences were found during acquisition. The neutral stimulus used in preacquisition subsequently was found to have a retarding effect on extinction, but there was no difference between $S s$ who had received paired and unpaired neutral stimuli initially.

Two untested ideas provided the impetus for this experiment. The first was that one thing that is learned in conditioning experiments may be the duration of the interval between CS and US. In this experiment we familiarized half of the Ss with the interval to be used prior to conditioning to see whether this would speed the progress of acquisition. The second idea stems from a common, but apparently unreported, informal observation in classical conditioning that sounds associated with the onset of the airpuff retard extinction if allowed to continue during the extinction trials. It seems necessary, however, to determine initially what is the effect of neutral stimuli on extinction. Since the operations involved in the test of these two ideas are similar, it proved convenient to study them both in a single experiment. Method

Sixty introductory psychology students were equally divided among the four groups presented in Table 1. Groups 1 and 2 received 10 trials of light and tone paired at the CS-US interval followed by 50 conditioning trials with the light and puff and 20 extinction trials. During extinction, Group 1 received a tone paired with the light at the CS-US interval while Group 2 received the light alone. Groups 3 and 4 received 10 initial trials of light and tone with the tone presented haphazardly followed by 50 acquisition trials and 20 extinction trials. Group 3 had a tone paired with the light during extinction and Group 4 received the light alone.

The laboratory was the same as that described elsewhere (Ominsky \& Kimble, 1966). The CS was a red spot of light presented by a Grason-Stadler multiple stimulus projector to Ss seated on a dental chair in a well illuminated soundproof IAC chamber. The US was a puff of air of $180 \mathrm{~mm} \mathrm{Hg}$ intensity presented to the corner of the S's right eye for a duration of $75 \mathrm{msec}$. The tone also had a duration of $75 \mathrm{msec}$ and was of a low intensity so as not to produce a

\begin{tabular}{|c|c|c|c|c|}
\hline \multirow[b]{2}{*}{ Groups } & \multicolumn{4}{|c|}{$\begin{array}{c}\text { Table } 1 \\
\text { Experimental Groups }\end{array}$} \\
\hline & $\begin{array}{l}\text { TRIALS: } \\
\text { PHASE: }\end{array}$ & $\begin{array}{c}1-10 \\
\text { Preacquisition }\end{array}$ & $\begin{array}{c}11-60 \\
\text { Acquisition }\end{array}$ & $\begin{array}{c}62-80 \\
\text { Extinction }\end{array}$ \\
\hline 1 & & CS, tone (paired) & CS-US & $\mathrm{CS}$, tone (paired) \\
\hline 2 & & CS, tone (paired) & CS-US & CS \\
\hline 3 & & $\mathrm{CS}$, tone (unpaired) & CS-US & $\mathrm{CS}$, tone (paired) \\
\hline 4 & & CS, tone (unpaired) & CS-US & CS \\
\hline
\end{tabular}

blink itself. For the pairings of CS-US and CS-tone the CS duration was $200 \mathrm{msec}$ and the CS-US and CS-tone intervals were $450 \mathrm{msec}$. The average intertrial interval was $20 \mathrm{sec}$ and varied randomly between 15 and 25 sec. A CR was defined as a deflection of $2 \mathrm{~mm}$ or more from a stable baseline from 180-475 msec after CS onset. If more than $50 \%$ of the responses fell in the interval 180-270 $\mathrm{msec}$, the $S$ was discarded as a "voluntary responder."

\section{Results and Discussion}

The curves in Fig. 1 show that there is no difference between the CS, tone (paired) and CS, tone (unpaired) groups during acquisition. A 2 by 2 analysis of variance of the CRs during extinction reveals the

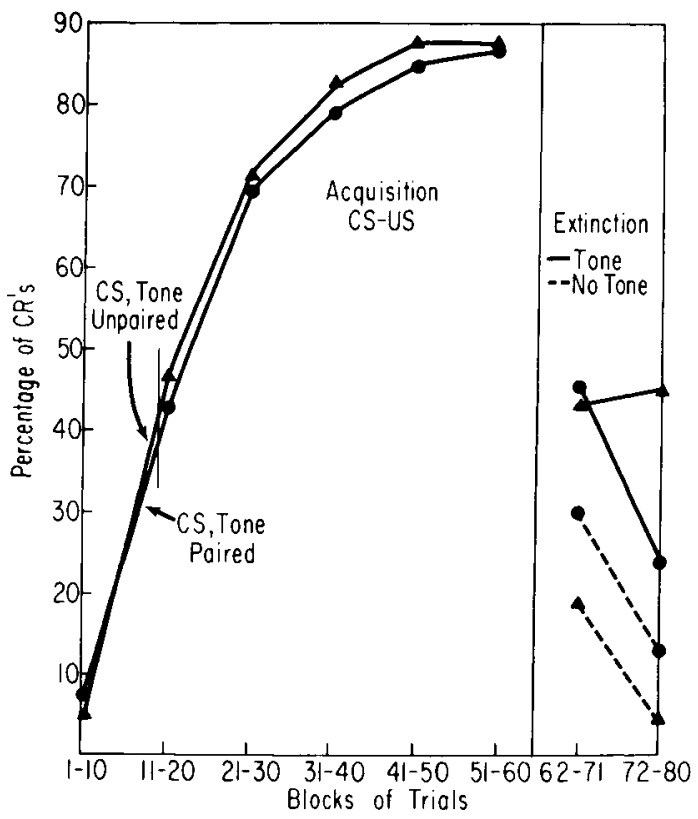

Fig. 1. Mean percentage of CR's in blocks of trials for preacquisition (Trials 1-10), acquisition (Trials 11-60), and extinction (Trials 62-80). 
effect of the tone during extinction to be significant in retarding extinction of the $\mathrm{CR}(\mathrm{F}=7.62, \mathrm{df}=1 / 44$, $p<.01)$. The effect of pairing the tone with the CS prior to acquisition had no effect on extinction ( $F$ $<1, \mathrm{df}=1 / 44$ ) and the interaction was not significant.

As regards our first untested idea, the results of this study indicate that pairing two neutral stimuli at the same interval as is subsequently used for classical eyeblink conditioning is not effective in facilitating the acquisition of CRs. Any of three factors may have worked against the demonstration of any such effect: (1) 10 familiarization trials may have been too few; (2) conditioning subsequent to these 10 trials was very rapid and this may have precluded the appearance of differences between groups; (3) S may not have attended to the tone during the initial phase. This last idea is supported indirectly by Walter et al (1964) who found no "contingent negative variation" (CNV) when a click was merely followed by flashes of light, but did find this surface negative conditioned response wave when $S$ had to attend to the second stimulus and respond to it. They also found this CNV or "expectancy wave" in the classical eyeblink conditioning situation.
The second result shows that a previously neutral stimulus was effective in retarding extinction. One possible explanation is that there is more of a change from acquisition to extinction when there is no stimulus at all following the CS than when the stimulus changes from a US (puff) to another stimulus (tone). A second explanation would maintain that the neutral stimulus helps to preserve the conditioning interval once it has been established. These two explanations are not incompatible, but further work is needed to determine their relative importance. The effect of sensitized responses to the tone seems ruled out by the lack of URs to the tone in the extinction phase.

\section{References}

OMINSKY, M., \& KIMBLE, G. A. Anxiety and eyelid conditioning. J. exp. Psychol, 1966, 71, 471-472.

WALTER, W. G., COOPER, R., ALDRIDGE, V.J., MoCALLUM, W.C., \& WINTER, A. L. Contingent negative variation: An electric sign of sensori-motor association and expectancy in the human brain. Nature, $1964,203,380-384$.

Notes

1. This study was supported by a grant (MH-08090) from the National Institute of Mental Health to Dr. Gregory A. Kimble. The authors thank Dr. Kimble for his valuable assistance.

2. Presently at Earlham College. 